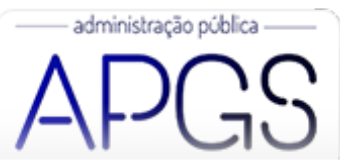

Administração Pública e Gestão Social ISSN: 2175-5787

apgs@ufv.br

Universidade Federal de Viçosa

Brasil

\title{
Popular Reporting à Luz da Teoria da Comunicação: Um Ensaio Teórico
}

Daniela Rodrigues, Juliana; Dias da Silva, Gabriela; Belloli de Vargas, Sandra Popular Reporting à Luz da Teoria da Comunicação: Um Ensaio Teórico

Administração Pública e Gestão Social, vol. 13, núm. 1, 2021

Universidade Federal de Viçosa, Brasil

Disponible en: http://www.redalyc.org/articulo.oa?id=351564966009

\section{(c) $(9 \Theta$}

Esta obra está bajo una Licencia Creative Commons Atribución-NoComercial-SinDerivar 3.0 Internacional. 


\title{
Popular Reporting à Luz da Teoria da Comunicação: Um Ensaio Teórico
}

\author{
Popular Reporting based on Communication Theory: a Theoretical Essay \\ Popular reporting a la luz de la Teoría de la Comunicación: un Ensayo Teórico
}

Juliana Daniela Rodrigues

Universidade do Vale do Rio dos Sinos, Brasil

Redalyc: http://www.redalyc.org/articulo.oa?

julianarodrigs@yahoo.com.br

Gabriela Dias da Silva

Universidade do Vale do Rio dos Sinos e Universidade

Federal do Rio Grande, Brasil

gabi.dias85@gmail.com

Sandra Belloli de Vargas

Universidade do Vale do Rio dos Sinos, Brasil

sandrabelloli@terra.com.br

Recepción: 12 Noviembre 2019

Aprobación: 26 Marzo 2020

Publicación: 01 Enero 2021

\section{Resumo:}

- Objetivo da pesquisa: O objetivo deste ensaio é explorar o tema popular reporting, à luz dos elementos e aspectos da Teoria da Comunicação, relacionando pontos a serem observados no processo de comunicação dos entes públicos com os cidadãos através dos relatórios financeiros.

- Enquadramento teórico: Teoria da Comunicação (Shannon, 1948) aplicada à contabilidade.

- Metodologia: Ensaio teórico, cujas discussões partiram de revisão da literatura sobre relatórios financeiros populares e teoria da comunicação aplicada à contabilidade encontrada em algumas das principais bases de dados para pesquisa acadêmica.

- Resultados: A comunicação através do popular reporting avança em relação aos relatórios financeiros de propósito geral, considerados os elementos e aspectos da teoria da comunicação. Atendendo às fragilidades apontadas, e adicionando mecanismos de envolvimento e diálogo com os cidadãos, pode ser esperada maior efetividade, participação e cidadania.

- Originalidade: O estudo analisa tema pouco explorado no país e indica a relação teórica do processo de comunicação das organizações públicas com os cidadãos por meio dos relatórios populares.

- Contribuições teóricas e práticas: $\mathrm{O}$ trabalho traz contribuição teórica ao relacionar o popular reporting à teoria da comunicação, vista a escassa análise de teorias em estudos sobre o tema. A contribuição prática se refere à organização dos pontos principais que podem guiar os profissionais na elaboração dos relatórios.

Palavras-chave: Contabilidade Aplicada ao Setor Público, Accountability, Transparência.

\section{AbSTRACT:}

- Research objectives: The objective of this essay is to explore "popular reporting" in the light of elements and aspects of the Theory of Communication, relating points to be observed in the process of communication between public entities and citizens through financial reports.

- Theoretical framework: Theory of Communication (Shannon, 1948) applied to accounting.

- Methodology: Theoretical essay. Discussions started from a literature review on popular financial reports and Theory of Communication applied to accounting found in some of the main databases for academic research.

- Results: Communication through popular reporting advances in relation to general purpose financial reports, considering the elements and aspects of the theory of communication. Given the problems pointed out and adding mechanisms of involvement and dialogue with citizens, greater effectiveness and social participation can be expected.

- Originality: The study analyzes a poorly explored topic in Brazil and indicates the theoretical relations of the communication process between public organizations and citizens through popular reports. 


\begin{abstract}
- Theoretical and practical contributions: The essay provides theoretical contributions by relating popular reporting to the theory of communication, given the scant analysis of theories in studies on the subject. Practical contribution refers to the organization of main points that can guide professionals in the preparation of reports.
\end{abstract}

KEYWORDS: Public sector accounting, Accountability, Transparency.

\title{
ReSUMEN:
}

- Objetivos de la investigación: El objetivo de este ensayo es explorar el "Popular Reporting" a la luz de elementos y aspectos de la Teoría de la Comunicación, relacionando puntos en el proceso de comunicación entre las entidades públicas y los ciudadanos a través de informes financieros.

- Marco teórico: Teoría de la comunicación (Shannon, 1948) aplicada a la contabilidad.

- Metodología: Ensayo teórico. Las discusiones comenzaron a partir de una revisión de la literatura sobre informes financieros populares y la Teoría de la Comunicación aplicada a la contabilidad que se encuentra en algunas de las principales bases de datos para la investigación académica.

- Resultados: La comunicación a través del "popular reporting" avanza en relación a los informes financieros de propósito general, considerando los elementos y aspectos de la teoría de la comunicación. Dada la problemática señalada y sumando mecanismos de implicación y diálogo con los ciudadanos, se puede esperar una mayor efectividad, participación y ciudadanía.

- Originalidad: El estudio analiza un tema poco explorado en Brasil e indica la relación teórica del proceso de comunicación entre las organizaciones públicas y los ciudadanos a través de informes populares.

- Aportes teóricos y prácticos: El ensayo brinda aportes teóricos al relacionar el "popular reporting" con la teoría de la comunicación, dado el escaso análisis de las teorías en los estudios sobre el tema. La contribución práctica se refiere a la organización de los puntos principales que pueden orientar a los profesionales en la elaboración de informes.

Palabras Clave: Contabilidad aplicada al sector público, Accountability, Transparencia.

\section{INTRODUÇÃO}

Os cidadãos têm exigido mais accountability de seus governos, principalmente maior transparência no que diz respeito à administração de recursos públicos, em razão da insatisfação com o desempenho e, consequente diminuição da confiança nos gestores públicos (Yusuf, Jordan, Neill, \& Hackbart, 2013). À medida que os governos crescem em tamanho e complexidade, muitos os veem como ineficientes e como agentes de desperdício na prestação de serviços públicos (Yusuf et al., 2013).

A accountability envolve questões como responsabilidade, controle, transparência, obrigação de prestação de contas e justificativas para as ações que foram ou deixaram de ser tratadas pelos responsáveis pela gestão pública (Pinho \& Sacramento, 2009). Um dos mecanismos utilizados pelas entidades do setor público para atendimento dessa requisição são os relatórios anuais, incluindo as demonstrações financeiras para fins gerais (Stanley, Jennings, \& Mack, 2008). A estrutura conceitual proposta nas normas internacionais atualmente vigentes no Brasil, Normas Brasileiras de Contabilidade Aplicada ao Setor Público (CFC, 2016), designa os cidadãos como usuários primários dos relatórios contábeis dos entes públicos, pois são recebedores de serviços do governo e provedores de recursos para esse fim.

Porém, existe preocupação com a complexidade dos relatórios e restam dúvidas quanto a sua eficácia como mecanismo de prestação de contas (Stanley et al., 2008). Os usuários dos relatórios governamentais são numerosos e diferem em termos de capacidade de compreensão e requisitos de informação, sendo contestável a visão de que as necessidades de todos os interessados podem ser satisfeitas por uma mesma forma de relatórios financeiros (Pérez, Hernández, \& Bolívar, 2005).

Quando o público não tem capacidade e tempo para se aprofundar nos conteúdos necessários para inspecionar as contas, os governos precisam facilitar a tarefa preparando declarações financeiras compreensíveis e abrangentes, visto que, ao reduzir o volume de informações, podem se tornar mais acessíveis ao público em geral (Chan, 2003). Para simplificar os mecanismos de accountability, surgiram os Popular Financial Reports (PFRs, popular reports, ou relatórios financeiros populares), que são direcionados a partes interessadas públicas (por exemplo, cidadãos, empresas e grupos comunitários) que não têm experiência ou 
conhecimentos em finanças públicas, mas que possuem direito a uma visão mais compreensível das atividades financeiras do setor público (Biondi \& Bracci, 2018).

Esses relatórios são principalmente difundidos na América do Norte (EUA e Canadá), existindo alguns casos práticos recentes no Brasil, como o Balanço Cidadão do Estado de Santa Catarina (Estado de Santa Catarina, 2019) e a Prestação de Contas Anual Simplificada do Estado da Bahia (Estado da Bahia, 2019). Porém, a abordagem acadêmica sobre o assunto tem sido limitada (Biondi \& Bracci, 2018).

O objetivo deste ensaio é explorar o tema popular reporting, à luz dos elementos e aspectos da Teoria da Comunicação (Shannon, 1948), relacionando pontos a serem observados no processo de comunicação dos entes públicos com os cidadãos e o papel dos contadores, como responsáveis pelas informações financeiras, na elaboração desse tipo de relatório. Assim, discute-se como a contabilidade pode auxiliar na accountability, transmitindo informações de maneira adequada à compreensão de seus usuários, no contexto do setor público.

O estudo contribui ao analisar um tema não amplamente explorado no país, mesmo em um contexto de questionamentos aos governantes por episódios de corrupção e do surgimento de legislação que visa suprir informações ao público, em especial a Lei Complementar no 131 de 2009, conhecida como Lei da Transparência. Além de trazer atenção a uma ferramenta pouco difundida e que pode ser útil na relação dos governantes com seu público, destacando pontos objetivos que podem guiar os profissionais em sua elaboração, o trabalho colabora trazendo a relação teórica do processo de comunicação das organizações públicas com os cidadãos por meio dos relatórios populares, conexão não localizada na literatura pesquisada.

Para revisão da literatura base para as discussões do ensaio, foram realizadas buscas, em outubro de 2019, em algumas das principais bases de pesquisa acadêmica (Periódicos CAPES, EBSCO, Emerald, Scopus, Science Direct e Web of Science), por meio dos termos "popular reporting", "popular financial reporting", e "communication theory" AND "accounting", em inglês e português. Foram selecionados, a partir da leitura dos resumos, quinze trabalhos pertinentes ao assunto relatórios financeiros populares e seis sobre a teoria da comunicação aplicada à contabilidade. Adicionalmente, foram revisadas referências encontradas nos artigos obtidos como resultado das buscas em bases de pesquisa, totalizando vinte e uma referências sobre o primeiro tema, e oito sobre o segundo.

O ensaio está subdividido, além desta introdução, em uma seção de revisão da literatura sobre popular financial reporting, seguida de uma seção de apresentação da teoria da comunicação, relacionando-a com a contabilidade. Por fim, uma seção de análise do tema popular reporting à luz da teoria da comunicação e as considerações finais do trabalho.

\section{Popular Reporting}

O tema popular reporting vem recebendo pouco interesse da academia, apesar de ter sido desenvolvido há mais de duas décadas na América do Norte, impulsionado por associações profissionais de contabilidade e finanças governamentais. A Government Finance Officers Association (GFOA), entidade que representa funcionários de finanças públicas nos Estados Unidos e no Canadá, promove premiação anual para os Popular Financial Reports desde 1991. O Governmental Accounting Standards Board (GASB), organização responsável pelas normas contábeis dos estados e municípios norte-americanos, editou a norma número 34 em 1999, colocando os cidadãos como público-alvo dos relatórios (GASB, 1999) e fortalecendo estes mecanismos de accountability.

Com menor detalhamento e menor uso de linguagem técnica, os PRFs apresentam um retrato verossímil, objetivo e preciso da situação governamental (Clay, 2007). Entre as características a serem observadas na sua elaboração elencadas por Clay (2007), devem estar a tempestividade, o escopo definido e a interligação com os relatórios financeiros tradicionais, fornecendo informações inteligíveis aos interessados. $\mathrm{O}$ autor acrescenta 
que a apresentação de dados comparativos, layout atrativo e o uso de elementos gráficos podem contribuir para disseminação adequada e interesse pelos usuários.

Os trabalhos sobre o tema podem ser divididos em cinco categorias: análise e propostas ao conteúdo dos relatórios, análise da perspectiva dos cidadãos, opiniões dos elaboradores dos demonstrativos, comparações com outros relatórios do setor público e benefícios da elaboração onde a ferramenta ainda não é utilizada. Como exceção às subdivisões apresentadas, encontra-se o estudo de Barbera, Borgonovi, \& Steccolini (2016) que triangularam diversas perspectivas, como documentos, elaboradores, cidadãos e imprensa acerca do relatório popular do município de Milão. Constatou-se que os relatórios populares podem melhorar a governança e foram apresentados quatro aspectos-chave: capacidade de assegurar maior transparência, neutralidade, maior participação e impactos na tomada de decisões.

Dentro das análises e propostas ao conteúdo dos popular reports, Sharp, Carpenter e Sharp (1998) apresentam diretrizes para a elaboração dos relatórios atestando que os contadores do setor público são qualificados para elaborar as informações financeiras destinadas a usuários sofisticados, mas que simplificar esse reporte não é uma tarefa fácil. Para isso, são discutidos detalhes de como estabelecer uma perspectiva do cidadão, com foco na interpretação, além da divulgação, objetividade e como tornar o relatório amigável ao usuário. Os autores reforçam que os relatórios populares não devem ser apenas documentos de relações públicas dos governantes, mas devem prestar contas aos cidadãos que os leem.

Ainda sob a perspectiva de que não é simples a adequação das informações financeiras ao público em geral, Marsh, Montondon, e Daniels (2004) e Marsh e Montondon (2005) utilizaram medidas de legibilidade para verificar se tais relatórios podem melhorar a compreensão do cidadão. Os resultados indicaram que há necessidade de os governos utilizarem redação mais compreensível, com esforço em adaptar o conteúdo à educação e à formação dos cidadãos.

Com a necessidade de atender o público-alvo para geração de popular reports de qualidade, a perspectiva do cidadão é analisada em alguns trabalhos. Yusuf e Jordan (2012) apresentaram um protótipo, concluindo que os relatórios ideais são curtos, visualmente atraentes e oportunos, fornecendo informações relevantes aos interesses e preocupações dos cidadãos e são amplamente distribuídos ao público. Os resultados de Jordan, Yusuf, Mayer e Mahar (2016) apontaram que as visões sobre as informações necessárias não estão limitadas a questões orçamentárias e fiscais, havendo interesse em questões não financeiras, assim, a agregação de informações contextualizadas e relevantes deve aumentar a utilidade aos usuários, se tornando estratégia para os governos interessados na aproximação e envolvimento da sociedade.

Neste sentido, Cohen, Mamakou, e Karatzimas (2017) foram além do que tange ao conteúdo dos relatórios, abordando a forma de apresentação e método de disseminação aos cidadãos. Os autores desenvolveram um relatório hipotético sob três formatos diferentes e um questionário para avaliar completude de informação, clareza, aparência visual, navegação, usabilidade, satisfação geral e imagem do município. As descobertas evidenciam que o site é capaz de superar outras formas de apresentação na maioria dos aspectos, fornecendo evidências de que o uso da tecnologia da informação e da comunicação é um meio de tornar os relatórios populares mais atraentes.

Yusuf, Jordan, Franklin e Ebdon (2017) estudaram a percepção do cidadão norte-americano em relação à accountability dos municípios utilizando o popular reporting entre os critérios analisados. Havia expectativa de que os residentes em cidades com altos níveis de transparência, acesso à informação e processos participativos percebessem a responsabilidade fiscal do governo local de forma mais positiva do que os demais. No entanto, os resultados demonstraram que a accountability percebida não variou, independentemente da disponibilização de ferramentas. As autoras sugerem que há uma lacuna acerca das atividades administrativas essenciais para informar e envolver os cidadãos, com consequente aumento da percepção de responsabilidade fiscal.

Jordan, Yusuf, Berman e Gilchrist (2017) analisaram os PRFs como mecanismos de transparência fiscal, utilizando um índice para o usuário cidadão, e compararam as divulgações dos governos locais dos Estados 
Unidos. Baseando-se na literatura existente sobre os índices de transparência e prestação de contas, foram compreendidas cinco áreas: compreensão, acesso, finanças, aparência e foco na comunidade. Os resultados indicaram que os PFRs apresentaram alta pontuação nos critérios de acesso e aparência. No entanto, os componentes restantes apontam fraquezas que podem refletir diretamente o desafio de tornar as informações financeiras compreensíveis para o cidadão não familiarizado com os termos técnicos da contabilidade.

Stanley et al. (2008) já haviam analisado de forma similar o cenário australiano por meio de um índice criado para avaliar a qualidade do conteúdo apresentado nos relatórios financeiros da comunidade, relatório financeiro popular difundido a partir da preocupação com a complexidade das demonstrações gerais do setor público. Os resultados demonstraram que a forma e o conteúdo dos demonstrativos variaram consideravelmente e as autoridades locais revelaram baixos índices de divulgação, bem como uma falta de análise do conteúdo das demonstrações.

Outros trabalhos investigaram a visão dos elaboradores dos popular reports. Lu (2007) investigou as mudanças nos relatórios após a aprovação do GASB no 34, que propôs a simplificação e a accountability na Géorgia. Os profissionais entrevistados sustentaram que o relatório ainda era complexo e repleto de jargões técnicos para cidadãos comuns. Em consequência, concluíram que enquanto os relatórios financeiros não incorporarem os relatórios populares, informando os cidadãos sobre a posição financeira, não haverá pessoas suficientes para forçar mudança na accountability do governo por meio de relatórios.

Kloby (2009) realizou entrevistas com diretores financeiros de governos locais para identificar motivaçõeschave, custos administrativos e benefícios instrumentais da tradução de orçamentos detalhados em relatórios amigáveis para os cidadãos. Os resultados demonstram que os diretores financeiros desempenham um papel de liderança na determinação do estilo e da extensão em que as informações financeiras são comunicadas ao público externo. Porém, a adoção dessa forma de relatório financeiro não gera, necessariamente, um impacto sobre a participação do cidadão no processo orçamentário, em consonância com o evidenciado por Yusuf et al. (2017).

Yusuf et al. (2013) e Yusuf e Jordan (2015) apresentaram resultados de pesquisas sobre o tema em entes públicos dos Estados Unidos e constataram que 75\% divulgam relatórios populares, com formatos e meios de divulgação variados. Dentre as motivações para tais publicações, encontraram o fornecimento de informações e a melhoria da transparência e accountability, por intermédio de relatórios financeiros de fácil compreensão. Onde não ocorre a divulgação, a principal justificativa encontrada foi a falta de recursos. Os autores enfatizam que parece haver desconexão entre a adoção e a entrega desses documentos para os cidadãos para que exerçam uma participação pública efetiva. Foi verificada a predominância de divulgação passiva, e a recomendação é que os governos envidem mais esforços para educar a população sobre a disponibilidade dos popular reports.

Os relatórios financeiros populares costumam concentrar-se nas informações financeiras e não são necessariamente organizados de forma conectada a outras informações operacionais que também são úteis para a accountability democrática (Lee, 2007). Nesse sentido, alguns autores realizaram abordagens comparativas com mecanismos de divulgação utilizados pelo setor público, sugerindo que sejam gerados relatórios populares que incluam informações relacionadas aos relatórios integrados e de sustentabilidade (Cohen \& Karatzimas, 2015; Biondi \& Bracci, 2018; Manes-Rossi, 2019).

Cohen e Karatzimas (2015) analisaram o popular reporting e os relatórios integrados. A comparação realizada pelos autores coloca as duas tendências como extremos em um "polo de complexidade", pois a primeira tenta apresentar informações financeiras em uma maneira simplificada, enquanto a outra envolve material adicional aos relatórios tradicionais. A conclusão é de que as entidades governamentais precisam dar o próximo passo nos relatórios originando a publicação de "Integrated Popular Reports (IPR)", conjugando, em linguagem e formato acessível, informações financeiras e operacionais que sejam de interesse do público.

Biondi e Bracci (2018) analisaram o popular reporting em conjunto com os relatórios integrados e os relatórios de sustentabilidade. É discutido que o surgimento e a difusão de inovações gerenciais dependem de vários fatores, em particular, de quem é o promotor e a sua legitimação dentro do grupo de organizações. É 
proposta, assim como por Cohen e Karatzimas (2015), uma única ferramenta de accountability por meio da fusão dos instrumentos estudados. Porém, é sinalizado o risco de que as inovações sejam apenas um modismo e que uma ferramenta de relatório abrangente possa ser tão ampla que acabe com seu próprio objetivo de ser fácil de ler e acessível a não especialistas.

Ao analisar novas tendências de accountability nos relatórios, Manes-Rossi (2019) comparou os diferentes tipos de relatórios alternativos existentes no setor público: relatório de sustentabilidade, relatórios populares, relatórios integrados, e relatórios populares integrados. Sobre o popular reporting, sustenta que tornar as finanças públicas compreensíveis é um primeiro passo, mas deve ser dada atenção à sua relação com a governança para manter conexão com outras ferramentas projetadas para interagir com os cidadãos, como audiências e orçamento participativo. Por fim, propõe o relatório popular integrado como a solução mais adequada, pois combina as informações financeiras com o que foi realizado em termos de serviços públicos, em uma visão simplificada, que pode demonstrar a criação de valor público para os cidadãos.

No caso de cenários onde o popular reporting ainda não é verificado, são encontrados estudos com o objetivo de estimular sua adoção. Para verificar a utilização das informações financeiras governamentais pelos cidadãos, Brusca e Montesinos (2006) conduziram um estudo na Espanha, averiguando se os cidadãos são usuários significantes das demonstrações financeiras governamentais. Foi examinada a relação entre relatórios financeiros e comportamento de voto em 143 municípios, encontrando que os resultados eleitorais são influenciados pelas informações financeiras. Os cidadãos demonstraram ser usuários das informações do governo local, embora não sejam produzidas com foco na comunidade, visto que os relatórios são de difícil localização e produzidos com foco em especialistas no tema, podendo ser de difícil compreensão até mesmo para alguns gestores da área. Frente a esses resultados, os autores defendem que haja mais "popular financial reports".

No mesmo sentido, Oliveira (2016) propôs que os relatórios financeiros populares podem ser o que Portugal precisa para tornar as informações do setor público mais transparentes e estabelecer uma melhor comunicação por parte dos municípios. Assim, questionou a pertinência de tal instrumento com objetivo de perceber quais as possíveis razões, características e vantagens obtidas se fosse adotado. Os resultados evidenciaram que o popular reporting pode constituir uma vantagem para a divulgação da informação financeira e de caráter institucional do município, de uma forma mais acessível, perceptível e em tempo útil (periodicidade mais frequente e disponibilizado na internet), permitindo uma maior transparência na relação município-cidadão.

Frente ao exposto, percebe-se que os relatórios populares avançam na accountability, mas que é preciso que evoluam no atendimento às necessidades dos usuários. Na literatura investigada foi possível constatar que existem deficiências em conteúdo, divulgação, compreensão e utilização. A iniciativa ainda não é praticada em muitos locais e existem diversas alternativas de formatos para sua elaboração. Analisando o popular reporting como um processo de comunicação do governo com seu público, à luz da teoria da comunicação e seus aspectos e elementos, podem ser elucidados pontos de suporte e contribuição para que atendam ao que se propõem em sua essência.

\section{Teoria da Comunicação e Contabiliddade}

A teoria da comunicação foi desenvolvida inicialmente por Claude Shannon (1948) como uma aplicação matemática ao campo das telecomunicações. Seu problema fundamental é a reprodução em um ponto de uma mensagem selecionada em outro ponto. A construção do autor foi adaptada a diferentes áreas de conhecimento, sendo discutida na contabilidade inicialmente por Bedford \& Baladouni (1962).

O modelo de Shannon (1948) para o processo de comunicação está estruturado em cinco elementos:

1. Fonte - Uma fonte de informação que produz uma mensagem ou sequência de mensagens para ser comunicada ao terminal de recepção. 
2. Transmissor - Aquele que opera na mensagem de alguma forma para produzir um sinal adequado para transmissão através do canal.

3. Canal - O meio utilizado para transmitir o sinal de transmissor para receptor.

4. Receptor - Executa a operação inversa daquela feita por o transmissor, reconstruindo a mensagem do sinal.

5. Destino - A pessoa (ou coisa) para quem a mensagem é destinada.

Segundo Li (1963), a teoria consiste no estudo desses elementos e sua interação. O autor traz que, além das partes do processo de comunicação, existem três aspectos de análise: o aspecto técnico trata da transmissão correta e eficiente da informação, que pode estar codificada, baseando-se na matemática e na física; o aspecto semântico enfatiza o conteúdo da informação transmitida, relacionada com a linguística e com a lógica; e o aspecto da efetividade diz respeito ao efeito sobre o destinatário da informação que está sendo transmitida, estando ligado à psicologia e sociologia.

A teoria da comunicação passou a ser aplicada à contabilidade em torno de uma década após a sua concepção e continua sendo utilizada até o momento. Nos estudos de comunicação, a comunicação da informação contábil ao público externo constitui uma área de aplicação específica para a investigação acerca do fenômeno (Merkl-Davies \& Brennan, 2017). Nesse contexto, a comunicação trazida através das informações contábeis é uma forma de comunicação organizacional externa, principalmente por meio de documentos narrativos corporativos, como é o caso das demonstrações financeiras (Merkl-Davies \& Brennan, 2017).

Seus conceitos orientam que a eficácia de uma mensagem é medida pela quantidade de informação assimilada e pelo volume de alternativas que ela permite ao usuário descartar pelo seu conhecimento (Dias Filho, 2000). Assim, a informação contempla a redução de incerteza, que no caso das informações contábeis pode ser verificada por meio da análise da mudança gerada no nível de incerteza do usuário depois de receber a mensagem transmitida pelas demonstrações financeiras (Dias Filho, 2000).

Bedford e Baladouni (1962), no estudo seminal relacionando a teoria da comunicação à contabilidade, identificaram elementos do processo da comunicação da matéria: os eventos econômicos, o profissional da contabilidade, os demonstrativos e seus usuários. Os autores abordaram a fidedignidade e significância como resultado esperado no fluxo da informação contábil. Para eles, embora existam variações entre os modelos de comunicação, todos eles contêm três elementos: a fonte, a mensagem e o destino da mensagem.

Os autores destacam que a mensagem é um elemento de comunicação comum tanto para o profissional de contabilidade como para o destinatário e para haver comunicação completa é necessário que seja produzida com integral fidelidade e interpretada totalmente. Entretanto, ponderam que as mensagens raramente são codificadas e decodificadas com total fidelidade, podendo sofrer distorções devido à existência de ruído, que sujeitam a qualidade de mensagens a variações. Na contabilidade, os ruídos podem ser definidos como os fatores que interferem na qualidade de suas mensagens e, por isso, deve haver esforços para sua redução (Bedford \& Baladouni, 1962).

Li (1963) estudou a dimensão semântica da comunicação aplicada à contabilidade, considerando a importância da linguagem, definida pelo autor como qualquer sistema que tenha um conjunto de símbolos e de regras relacionados às operações desses símbolos. Assim, a contabilidade, tendo palavras e números como seus símbolos e tendo procedimentos e convenções como suas regras, pode ser considerada como um sistema de linguagem. $\mathrm{O}$ autor conclui que as demonstrações contábeis, por relatarem transações cuja existência e magnitude monetária são definidas, alcançam o estabelecido na teoria da comunicação no que diz respeito ao nível semântico, transmitindo somente informações factuais.

Smith e Smith (1971) realizaram um dos primeiros trabalhos empíricos sobre o tema, associando a teoria da comunicação à readability das notas explicativas das maiores empresas norte-americanas. Foi adotada a premissa de que a função de relatório financeiro é comunicar informações financeiras selecionadas. Se esta função não é executada, então o documento não é útil e para que isso não ocorra, o destino da mensagem 
deve ser capaz de compreender a mensagem selecionada pelo fornecedor de informações. A fim de verificar se a contabilidade estava executando a função de comunicação por meio da transferência de significado, foram aplicadas medidas de readability às notas explicativas. Os autores concluíram que a legibilidade do conteúdo das notas explicativas analisadas era restrita, prejudicando a comunicação.

No Brasil, os estudos de Dias Filho (2000) e Dias Filho e Nakagawa (2001) são os primeiros sobre o tema. Os autores relacionaram a teoria da comunicação à contabilidade, com a elaboração de ensaios teóricos, discutindo principalmente acerca da dimensão semântica. É debatida a compreensibilidade pelos usuários dos termos empregados nos demonstrativos, com a hipótese de que o usuário médio das informações contábeis pode não ser capaz de compreender totalmente o seu conteúdo, seja por não estar familiarizado aos termos técnicos empregados na evidenciação ou por interpretá-los com significados diferentes dos que a contabilidade aplica de forma geral. Assim, a utilidade da informação transmitida estaria prejudicada.

Entre os estudos mais recentes, é encontrada uma abordagem no setor público feita por Williams (2015). A autora ampliou a compreensão sobre o papel da comunicação nos relatórios de sustentabilidade de governos australianos focalizando em três elementos: nível de compreensão e conscientização, formato de relatório de sustentabilidade e importância do envolvimento da comunidade. A pesquisa evidenciou que não havia um nível equilibrado de compreensão e conscientização em relação aos demonstrativos em questão. Ao analisar a comunicação, identificou que é realizada de maneira formal por meio dos relatórios anuais, porém a maioria ocorre de maneira informal com uso do relato verbal. Foi demonstrado baixo nível de interesse em se envolver com a comunidade por parte dos entrevistados. Especialmente, esse elemento demonstra que o relatório de sustentabilidade é utilizado para informar de modo geral e amplo a comunidade, caracterizando um processo unilateral que não oportuniza retroalimentação e melhorias.

Merkl-Davies e Brennan (2017) fornecem uma análise robusta do arcabouço teórico de comunicação contábil externa analisando perspectivas, tradições e teorias da disciplina de estudos de comunicação. Os autores subdividem a estrutura teórica em duas perspectivas de pesquisa sobre comunicação contábil: perspectiva de transmissão funcionalista-comportamental e perspectiva narrativa, interpretativa e simbólica. Os resultados apontam que os estudos anteriores enfocam predominantemente o papel das divulgações discricionárias no relacionamento entre as organizações e seus públicos, com a comunicação contábil sendo tratada principalmente como a transmissão de mensagens sobre informações financeiras, ambientais e sociais para o público externo. Os autores incentivam que as pesquisas futuras utilizem tradições alternativas, indo além do comunicador e da mensagem, e explorando o engajamento entre as organizações e seus públicos de forma a promover diálogos que permitam interação sobre questões de contabilidade e prestação de contas.

Conforme abordado no estudo de Merkl-Davies e Brennan (2017), houve refinamentos subsequentes na literatura para o modelo original de Shannon (1948), que se enquadra na perspectiva de transmissão funcionalista-comportamental predominante nos estudos. Dentre estes aprimoramentos, encontra-se o reconhecimento de um mecanismo de feedback pelo receptor, mas os elementos principais são constantes e formam os fundamentos da análise neste estudo.

Mesmo que os estudos sobre a teoria da comunicação e a contabilidade existam há várias décadas, ainda não são numerosos e indicam espaço para evolução. A aplicação no setor público é bastante restrita (Williams, 2015), não sendo identificados trabalhos conectando o tema ao popular reporting. Assim, as divulgações financeiras do setor público carecem de análise como um processo de comunicação, dado o número de stakeholders e sua habilidade de compreensão das informações contidas nesses informes, ponto que o presente ensaio se propõe a explorar.

\section{Popular Reporting à Luz da Teoria da Comunicação}

A utilização de lentes teóricas para a análise do popular reporting é pouco verificada na literatura revisada. Os trabalhos costumam utilizar os conceitos de transparência, accountability e governança pública para 
condução das discussões. O presente ensaio busca ampliar a visão do assunto, apresentando a divulgação de relatórios financeiros populares como uma ferramenta de comunicação do setor público com os cidadãos.

Após as revisões de literatura apresentadas nas seções prévias, a presente seção busca trazer relações entre os dois assuntos tratados. Para condução das análises, partiu-se da identificação de pontos relacionados aos elementos (fonte, transmissor, canal e destinatário) e aspectos (técnico, semântico e efetividade) pertinentes ao processo de comunicação, com base da teoria de Shannon (1948) e subsequentes aplicações à contabilidade, na leitura dos trabalhos sobre popular reporting. Verificadas relações entre os temas, foi construída adaptação dos elementos do processo de comunicação ao popular reporting, foram analisadas questões que podem colaborar para uma melhor elaboração e divulgação da ferramenta e apresentadas discussões sobre potencialidades e desafios, destacando o papel do contador do setor público.

O termo "comunicação" é constantemente verificado na literatura sobre popular reporting. Por exemplo, Brusca e Montesinos (2006) argumentam que as informações contábeis colaboram na divulgação do que foi realizado pelas políticas públicas, podendo servir como um meio de comunicação dos efeitos econômicos da gestão política. Yusuf et al. (2013) sustentam que o fornecimento das informações financeiras dos governos no formato popular pode facilitar a comunicação entre o governo e os cidadãos de forma que atenda as metas democráticas de responsabilidade e de transparência. Já Barbera et al. (2016) acrescentam que a comunicação pode ser uma maneira útil de conscientizar os cidadãos sobre a disponibilidade e uso de recursos públicos, sendo que os relatórios populares podem auxiliar informando suas decisões e fornecendo subsídios para processos políticos de alocação de recursos.

O popular reporting é considerado uma ferramenta de relações públicas (além de informação financeira) por Sharp et al. (1998). No mesmo sentido, Yusuf et al. (2013) propõem compartilhamento de recursos para o seu desenvolvimento entre áreas de informações financeiras, de comunicação e de relações públicas do ente, a fim de minimizar o peso de verbas oriundas de uma única área governamental. Tais colocações também favorecem a visão da ferramenta como integrante do processo de comunicação do governo com seu maior público e indicam a pertinência da análise do popular reporting à luz dos elementos e aspectos da teoria da comunicação

A divulgação de relatórios financeiros populares pode ser analisada como um processo de comunicação, já que a finalidade do popular reporting é aproximar o cidadão das informações financeiras do governos e que tais informações constam da contabilidade. Isso ocorre uma vez que o objetivo do componente de comunicação é alcançado caso o destino atribua o significado pretendido pela informação fonte para a mensagem selecionada (Smith \& Smith, 1971).

A partir de análise da literatura sobre popular reporting e acerca da teoria da comunicação aplicada à contabilidade, é possível identificar dentre os elementos do processo de comunicação de Shannon (1948) uma relação com a comunicação por meio do popular reporting. Adaptando a construção de Dias Filho e Nakagawa (2001) para os sistemas contábeis, os elementos podem ser verificados da seguinte forma: os eventos econômicos do setor público são as fontes básicas; o contador do ente público atua como transmissor, observando estes eventos e codificando-os de maneira simplificada para transmitir a informação por meio dos relatórios populares os quais formam o canal básico desse tipo de comunicação. Finalmente, a mensagem é recebida, decodificada e interpretada pelo cidadão, que figura no processo como destinatário final.

Ultrapassando os aspectos originais da teoria da comunicação, considerando que o cidadão não é um receptor passivo e que pode manter diálogo e participação ativa nos fenômenos dos entes públicos, deve-se pensar em avanços para que haja maior retroalimentação nesse processo. Assim, a democracia poderia efetivamente alterar a fonte da mensagem, fazendo com que fenômenos econômicos do governo atendam aos desejos dos usuários de maneira cíclica. Para analisar este aspecto, é necessário avançar nas teorias de comunicação de tradições alternativas, de modo a explorar o relacionamento das organizações governamentais com seus diversos públicos de forma a dialogar e buscar maior interação nos pontos relacionados às finanças e à prestação de contas, conforme proposta de Merkl-Davies e Brennan (2017). 
Segundo os autores, a pesquisa da comunicação na contabilidade tem se limitado ao transmissor e à mensagem. A Figura 1 demonstra o processo de comunicação do popular reporting adaptado de Dias Filho e Nakagawa (2001), avançando com a inclusão da resposta do destinatário (cidadão) que pode influenciar a fonte Merkl-Davies e Brennan (2017).

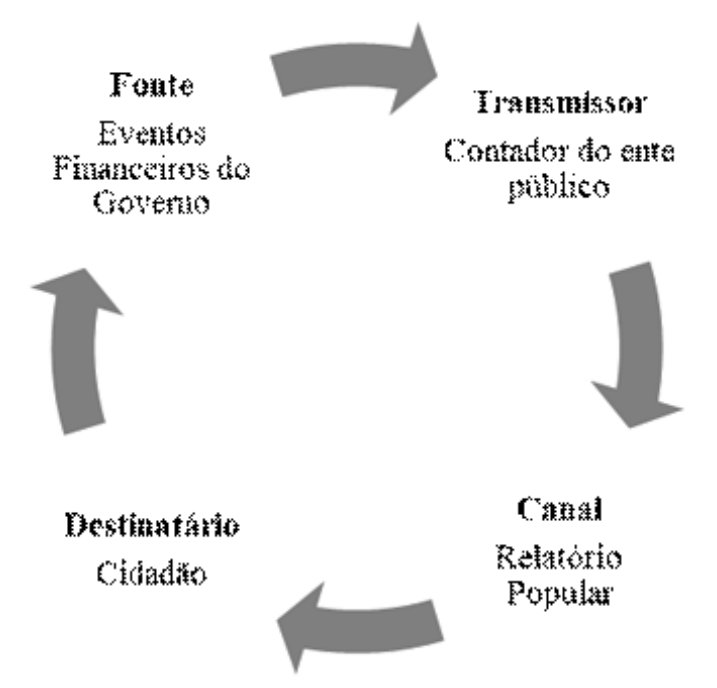

Figura 1 - O processo de comunicação do popular reporting

Fonte: Elaborado pelas autoras, adaptado de Dias Filho e Nakagawa (2001).

Nos estudos sobre popular reporting verificam-se como unidades de análise alguns dos elementos do processo de comunicação. Por exemplo, abordagens das motivações e dificuldades para implementação do relatório por parte do transmissor (Kloby, 2009; Yusuf et al., 2013; Yusuf \& Jordan, 2015) outros versaram sobre a análise do canal, como o conteúdo do relatório (Jordan et al., 2017; Marsh et al., 2004; Marsh \& Montondon, 2005; Stanley et al., 2008) ou comparações com diferentes tipos de relatórios (Biondi \& Bracci, 2018; Cohen \& Karatzimas, 2015). Ainda, encontram-se pesquisas realizadas na perspectiva do destinatário, como os casos de estudos com as impressões dos cidadãos (Cohen et al., 2017; Jordan et al., 2017; Jordan et al., 2016). Esses trabalhos apontam considerações importantes a serem observados na elaboração dos relatórios, sob a perspectiva de cada um dos elementos, para um melhor processo de comunicação.

Os três aspectos envolvidos na teoria da comunicação trazidos por Li (1963) também são observáveis no popular reporting: técnico, semântico e efetividade. As principais questões e recomendações levantadas da literatura analisada acerca desses pontos estão elencadas na Figura 2. $\mathrm{O}$ aspecto técnico, que trata da transmissão correta e eficiente, pode ser verificado nos estudos que questionam os métodos de divulgação, como Cohen et al., (2017) cujos resultados mostram que, na perspectiva do cidadão, a internet proporciona uma disseminação mais rápida e amigável. Tal aspecto pode ser verificado em Yusuf et al., (2013), que encontram uma carência de disseminação ativa dos relatórios populares, o que dificultaria a transmissão da informação até os destinatários. 
Figura 2 - Aspectos da teoria da comunicação evidenciados no popular reporting.

\begin{tabular}{|l|l|}
\hline $\begin{array}{l}\text { Aspecto da } \\
\text { Teoria da } \\
\text { Comunicação }\end{array}$ & Pontos destacados da literatura sobre popular reporting \\
\hline Técnico & $\begin{array}{l}\text { - Utilização de visual estimulante, facetas de design, ilustrações, comunicação e inovação são mais } \\
\text { prováveis que atraiam os usuários (Clay, 2007; Stanley et al., 2008; Jordan et al., 2017). } \\
\text { - Número de páginas e tamanho de fonte que sejam razoáveis (Stanley et al., 2008; Jordan et al., } \\
\text { 2017). } \\
\text { - O site supera outras formas de apresentação na maioria dos aspectos (Cohen et al., 2017). } \\
\text { - Outros formatos possíveis para os relatórios populares (Cohen \& Karatzimas, 2015; Biondi \& } \\
\text { Bracci, 2018; Manes-Rossi, 2019). } \\
\text { - Carência de disseminação ativa dificulta a transmissão da informação até os destinatários (Yusuf } \\
\text { et al., 2013). }\end{array}$ \\
\hline Semântico & $\begin{array}{l}\text { - Necessidade de estabelecer uma perspectiva do cidadão, foco na interpretação além da } \\
\text { divulgação, objetividade e tornar o relatório amigável ao usuário (Sharp et al., 1998). } \\
\text { - Redação compreensível, "readability" de acordo com índices como o de Flesch-Kincaid. (Marsh, } \\
\text { Montondon, \& Daniels, 2004; Marsh \& Montondon, 2005, Jordan et al., 2017). } \\
\text { - Com menor detalhamento e menor uso de linguagem técnica, os PRFs podem apresentar um } \\
\text { retrato verossímil, objetivo e preciso da situação governamental (Clay, 2007). }\end{array}$ \\
\hline Efetividade & $\begin{array}{l}\text { - Os relatórios não devem ser apenas documentos de relações públicas dos governantes, mas } \\
\text { devem prestar contas (Sharp et al., 1998). } \\
\text { - A adoção dessa forma de relatório não gera necessariamente um impacto sobre a participação do } \\
\text { cidadão (Kloby, 2009; Yusuf et al., 2017) } \\
\text { - Os relatórios populares podem fornecer aos cidadãos informações sobre questões orçamentárias } \\
\text { públicas necessárias para participar conscientemente dos processos de tomada de decisão (Barbera } \\
\text { et al., 2016) } \\
\text { - Risco de que as inovações em prestação de contas ser um modismo, criando ineficiências e não } \\
\text { atingindo os objetivos pretendidos (Biondi \& Bracci, 2018). }\end{array}$ \\
\hline
\end{tabular}

Fonte: elaborado pelas autoras.

No processo de comunicação, pode haver um problema semântico, caso o significado que um emissor pretende transmitir por meio de determinado código não seja adequadamente interpretado pelo receptor da mensagem (Dias Filho \& Nakagawa, 2001). Essa é a principal questão motivadora do surgimento dos demonstrativos populares, derivada da necessidade de trazer informações a usuários que não tem entendimento em finanças públicas, transmitindo uma mensagem compreensível ao cidadão. São encontrados alguns trabalhos com o fim de verificar se estão alcançando o objetivo desejado analisando a linguagem utilizada (Stanley et al., 2008; Jordan et al., 2017). A readability, tratada em estudos de comunicação e contabilidade (Smith \& Smith, 1971) e também no caso dos relatórios populares (Marsh et al., 2004; Marsh \& Montondon, 2005; Jordan et al., 2017) inclui-se neste aspecto, pois mede a facilidade de leitura que encontra-se nos objetivos dos PFRs.

O último aspecto, a efetividade, vai além do recebimento e do entendimento pelo usuário da informação. Diz respeito ao alcance do objetivo sobre o comportamento do destinatário da informação que está sendo transmitida. No caso do popular reporting, deve ser verificado como o recebimento da informação e a compreensão pelo cidadão podem afetar a maneira como ele age em um ambiente democrático. Para a accountability recebida, é necessário observar como pode influenciar comportamentos em relação ao governo. Brusca e Montesinos (2006) constataram relação entre a divulgação das informações financeiras e o comportamento de voto no cenário espanhol, indicando que a comunicação pode trazer resultados nos comportamentos dos cidadãos. Barbera et al. (2016) colocam que os relatórios populares podem fornecer aos cidadãos informações sobre questões orçamentárias públicas necessárias para participar conscientemente dos processos de tomada de decisão. 
Os relatórios também podem promover uma comunicação mútua, permitindo ao cidadão participar da gestão com mais proatividade (Barbera et al., 2016). Porém, existem estudos (Kloby et al. 2009; Yusuf et al., 2017) evidenciando que a adoção dessa forma de relatório financeiro, mesmo atendendo ao objetivo de prestação de contas, não gera necessariamente um impacto sobre a participação do cidadão no processo orçamentário. Na mesma linha, Williams (2015) encontrou baixo nível de interesse em envolvimento com a comunidade por parte dos elaboradores em análise do processo de comunicação do relatório de sustentabilidade de entes públicos australianos.

A análise indica que mesmo nos cenários onde os relatórios populares já são difundidos há algum tempo, são identificados pontos a melhorar em todos os aspectos (técnico, semântico e efetividade) contemplados pela teoria da comunicação. Ainda que esteja sendo disponibilizada a ferramenta adicional e simplificada aos usuários, não se pode assegurar que atende plenamente ao objetivo. Destaca-se que o processo de comunicação tem sido linear, pois não foram identificados pontos que viabilizem resposta pelo cidadão após recebimento da mensagem confome estabelecido pelo processo de comunicação, reforçando o resultado encontrado por Merkl-Davies e Brennan (2017) na pesquisa sobre contabilidade.

Cabe analisar se a baixa participação e resposta dos cidadãos às divulgações encontradas por alguns autores (Kloby et al. 2009; Yusuf et al., 2017) são verificadas devido à ausência de mecanismos de comunicação mútua, ou se as deficiências verificadas em formato, carência de informações de interesse, disseminação insuficiente, entre outras oriundas das pesquisas sobre o tema e relacionadas aos aspectos da teoria da comunicação, geram esse fenômeno. Portanto, ambas possibilidades devem ser ponto de atenção dos contadores e demais envolvidos na elaboração dos relatórios financeiros populares.

Identificados desafios de disseminação da ferramenta de modo que gere aumento da percepção de responsabilidade fiscal pelos cidadãos (Yusuf et al., 2013), surpreende a carência de pesquisas analisando a utilização de mídias sociais, recursos de amplo acesso pela população, para essa finalidade. Cohen et al. (2017) discorrem brevemente sobre o meio de divulgação, seu baixo custo e possibilidade de resposta e engajamento pelos cidadãos. Porém, as pesquisas sobre popular reporting não se aprofundam em sua propagação em redes como Facebook e Twitter, que poderiam ser solução para problemas técnicos e de efetividade sob a ótica da teoria da comunicação.

Apesar da necessidade de evolução no processo de comunicação, a iniciativa avança em comparação aos relatórios financeiros para fins gerais do setor público. As relações apresentadas entre a literatura de popular reporting e teoria de comunicação identificam o potencial da ferramenta em contribuir para uma melhor prestação de contas dos governos ao público amplo. Analisando sob o aspecto semântico da teoria da comunicação, por sua simplificação que possibilita maior compreensão pelos não familiarizados com termos contábeis. Assim, torna a mensagem (eventos financeiros do setor público) possível de ser melhor interpretada pelo destinatário (cidadão), reduzindo ruídos na comunicação (Bedford \& Baladouni, 1962).

Cabe aos contadores, como responsáveis pela publicação informações financeiras, e consequentemente transmissores da mensagem no processo de comunicação, impulsionarem a elaboração e divulgação desse tipo de relatório em conjunto com as áreas de comunicação dos governos. Além de atuarem na simplificação da linguagem, adequação de formato e disseminação, os profissionais contam com o desafio de ultrapassar a fronteira das informações financeiras, conectando-as com outras áreas de interesse dos usuários, necessidade manifestada na pesquisa de de Jordan et al. (2016).

Nesse ponto, cabe orientar que sejam direcionados esforços no sentido de identificar as possibilidades de novos formatos de relatórios, ponto relacionado ao canal trazido no processo de comunicação de Shannon (1948) como meio utilizado para transmitir o sinal pelo transmissor e ao aspecto técnico. As pesquisas sobre o tema sugerem conjugação entre ferramentas como relatórios integrados e de sustentabilidade (Cohen \& Karatzimas, 2015; Biondi \& Bracci, 2018; Manes-Rossi, 2019).

Apesar da missão de simplificação não ser uma tarefa simples aos profissionais de contabilidade (Sharp et al., 1998), e serem diversas questões a serem observadas para a comunicação pelo popular reporting, o presente 
trabalho apresenta pontos e relações que podem ser úteis em sua elaboração e divulgação. A promoção de uma ferramenta de accountability de maior alcance pode ser vista como uma oportunidade, valorizando o trabalho dos profissionais envolvidos, com a prestação de um serviço mais reconhecido pelos cidadãos.

\section{Considerações Finais}

O presente estudo explorou o tema popular reporting, pouco tratado em pesquisas no país, revisando a literatura à luz da Teoria da Comunicação aplicada à contabilidade. Foi possível estabelecer relações entre as abordagens dos estudos sobre o popular reporting e os elementos e aspectos da Teoria Matemática da Comunicação, pautando pontos a serem observados no processo de comunicação dos entes públicos com os cidadãos, e o papel dos contadores, como responsáveis pelas informações financeiras, na elaboração desse tipo de relatório.

A discussão realizada, apresentando relações distintas entre os dois temas, teve como destaques a adaptação da construção de Dias Filho e Nakagawa (2001) para os elementos do processo de comunicação e a apresentação de pontos relacionados aos aspectos técnico, semântico e de efetividade oriundos dos trabalhos revisados sobre popular reporting. O estudo acrescentou à literatura, vista a escassa utilização de teorias em estudos sobre o tema, e aos elaboradores dos relatórios, em especial os contadores do setor público, que poderão acessar uma relação de questões a serem consideradas para uma efetiva comunicação das informações financeiras do governo com os cidadãos.

Pode ser concluído que, apesar das deficiências identificadas nos três aspectos do processo de comunicação, a ferramenta avança em relação aos relatórios financeiros de propósito geral, especialmente no aspecto semântico, por trazer esforços de simplificação aos conceitos técnicos. Atendendo às fragilidades apontadas e avançando na adaptação da teoria da comunicação ao popular reporting, para adicionar mecanismos práticos de maior envolvimento e diálogo com os cidadãos, conforme proposta das teorias alternativas para a comunicação apontadas por Merkl-Davies e Brennan (2017), pode ser esperada uma efetividade mais representativa da comunicação e que os cidadãos respondam às informações recebidas com aumento na participação e cidadania.

Trata-se de um desafio pois a análise da comunicação na contabilidade é restrita de uma forma geral e tem se concentrado no transmissor e mensagem (Williams, 2015; Merkl-Davies e Brennan, 2017). Além disso, apesar de alguns trabalhos apresentarem os relatórios populares como ferramentas para engajamento do cidadão (Brusca \& Montesinos, 2006; Barbera et al., 2016), outros relatam que a participação do público não é verificada (Kloby, 2009; Yusuf et al., 2017). Cabe aos contadores e às áreas de comunicação dos governos a missão de, atentos às deficiências apresentadas, difundirem os relatórios buscando meios que ampliem a resposta às informações recebidas pelos usuários, o que pode ser recompensado com maior destaque aos seus trabalhos perante os cidadãos.

O Brasil encontra-se em um cenário de grandes ações em direção à accountability, com obrigações legais de divulgações de informações em portais de transparência e do fornecimento do acesso à informação pelos cidadãos. Porém, para que uma base de informações seja eficaz aos usuários, ela deve estar acessível em dois sentidos da palavra, sendo disponível e inteligível (Justice, 2006). Pouco se trata sobre a simplificação dos termos técnicos utilizados para melhor compreensão pelos usuários no país, ponto em que a disponibilização de relatórios financeiros populares tem potencial de trazer avanços.

Nesse sentido, espera-se que este ensaio contribua na disseminação de iniciativas, buscando a comunicação das informações contábeis governamentais em um formato amigável para o cidadão, observando os pontos relacionados ao processo de comunicação. Também há expectativa de que seja direcionada atenção da academia às divulgações financeiras governamentais em formato popular, visto que a transparência do setor público vem sendo objeto de estudos há mais de uma década (Neto, Cruz \& Ensslin, 2007). A escassez de interesse acadêmico acerca do popular reporting surpreende, pois os recursos públicos têm diminuído e as 
expectativas dos cidadãos estão se tornando cada vez maiores e mais sofisticadas, o que aumenta os desafios e as exigências impostos aos governantes (Barbera et al., 2016).

Para estudos futuros, sugere-se a análise de iniciativas práticas de popular reporting nos entes públicos brasileiros, bem como os aspectos que originam o interesse dos governantes na realização de tais divulgações. A proposta de um formato que atenda às necessidades dos cidadãos no contexto do país, além da disseminação por meios de comunicação alternativos, como as mídias sociais, pode ser útil aos objetivos do relatório. Por fim, a incorporação de aspectos de outras correntes de análise da comunicação, permitindo uma efetiva participação popular, podem ser passos posteriores que virão a preencher lacunas na literatura referente ao tema.

\section{REFERÊNCIAS}

Barbera, C., Borgonovi, E., Steccolini, I. (2016). Popular reporting and public governance: The case of "bilancio in arancio" in milan municipality. In Governance and Performance in Public and Non-Profit Organizations (pp. 3-30). doi: https://doi.org/10.1108/S2051-663020160000005001

Bedford, N. M., Baladouni, V. (1962). A Communication Theory Approach to Accountancy. The Accounting Review, $37(4), 650-659$.

Biondi, L., Bracci, E. (2018). Sustainability, popular and integrated reporting in the public sector: A fad and fashion perspective. Sustainability (Switzerland), 10(9), 1-16. doi: https://doi.org/10.3390/su10093112

Brusca, I., Montesinos, V. (2006). Are citizens significant users of government financial information? Public Money and Management, 26(4), 205-209. doi: https://doi.org/10.1111/j.1467-9302.2006.00526.x

Chan, J. L. (2003). Government accounting: An assessment of theory, purposes and standards. Public Money and Management, 23(1), 13-20. doi: https://doi.org/10.1111/1467-9302.00336

Clay, J. A. (2007). Popular reporting. Government Public Relations: A Reader.

Cohen, S., Karatzimas, S. (2015). Tracing the future of reporting in the public sector: introducing integrated popular reporting. International Journal of Public Sector Management, 28(6). doi: https://doi.org/10.1108/IJPSM-112014-0140

Cohen, S., Mamakou, X. J., Karatzimas, S. (2017). IT-enhanced popular reports: Analyzing citizen preferences. Government Information Quarterly, 34(2), 283-295. doi: https://doi.org/10.1016/j.giq.2017.04.003

Conselho Federal de Contabilidade (CFC) (2016). NBC TSP Estrutura Conceitual, CFC, Brasília. Recuperado de h ttp://www1.cfc.org.br/sisweb/SRE/docs/NBCTSPEC.pdf

Dias, J. M., Filho (2000). A linguagem utilizada na evidenciação contábil: uma análise de sua compreensibilidade à luz da teoria da comunicação. Caderno de Estudos, (24), 38-49. doi: http://dx.doi.org/10.1590/S1413-925120 00000200003

Dias, J. M., Filho, Nakagawa, M. (2001). Análise do processo da comunicação contábil: uma contribuição para a solução de problemas semânticos, utilizando conceitos da teoria da comunicação. Revista Contabilidade \& Finanças, 12(26), 42-57. doi: http://dx.doi.org/10.1590/S1519-70772001000200003

Estado de Santa Catarina (2019). Balanço Cidadão 2018: Estado de Santa Catarina. Florianópolis: Secretaria de Estado da Fazenda. Recuperado de http://www2.sef.sc.gov.br/transparenciasc/balanco-geral-do-estado/2018/Balanco Cidadao2018.pdf

Estado da Bahia (2019). Prestação de Contas Anual Simplificada 2018. Salvador: Secretaria da Fazenda do Estado, Diretoria de Contabilidade Pública. Recuperado de http://www.transparencia.ba.gov.br/Home/ObterDocum entoHome/PrestacaoContasAnual Simplificada2018

Governmental Accounting Standards Board (GASB) (1999). Statement No. 34 of the Governmental Accounting Standards Board: basic financial statements and management's discussion and analysis for state and local governments. Retrieved from https://www.gasb.org/jsp/GASB/Document_C/DocumentPage?cid=11761600 29121\&acceptedDisclaimer $=$ true 
Jordan, M. M., Yusuf, J. E., Berman, M., Gilchrist, C. (2017). Popular Financial Reports as Fiscal Transparency Mechanisms: An Assessment Using the Fiscal Transparency Index for the Citizen User. International Journal of Public Administration, 40(8), 625-636. doi: https://doi.org/10.1080/01900692.2016.1186175

Jordan, M., Yusuf, J. E. W., Mayer, M., Mahar, K. (2016). What citizens want to know about their government's finances: Closing the information gap. Social Science Journal, 53(3), 301-308. doi: https://doi.org/10.1016/j.s oscij.2016.04.007

Justice, J. B., Melitski, J., Smith, D. L. (2006). E-government as an instrument of fiscal accountability and responsiveness: Do the best practitioners employ the best practices? The American Review of Public Administration, 36(3), 301-322.

Kloby, K. (2009). Less is more: exploring citizen-based financial reporting in local government. Journal of Public Budgeting, Accounting \& Financial Management, 21(3), 368-392. doi: https://doi.org/10.1108/JPBAFM-2103-2009-B002

Lee, M. (2007). The history of municipal public reporting.International Journal of Public Administration, 29(4-6), 453-476. doi: https://doi.org/10.1080/01900690500436982

Lei complementar n. 131, de 27 de maio de 2009 (2009). Acrescenta dispositivos à Lei Complementar n. 101, de 4 de maio de 2000, que estabelece normas de finanças públicas voltadas para a responsabilidade na gestão fiscal e dá outras providências, a fim de determinar a disponibilização, em tempo real, de informações pormenorizadas sobre a execução orçamentária e financeira da União, dos Estados, do Distrito Federal e dos Municípios. Brasília, DF. Recuperado de http://www.planalto.gov.br/ccivil_03/LEIS/LCP/Lcp131.htm

Lei n. 12.527, de 18 de novembro de 2011 (2011). Regula o acesso a informações previsto no inciso XXXIII do art. 50 , no inciso II do $\$ 3$ o do art. 37 e no $\$ 2$ o do art. 216 da Constituição Federal; altera a Lei no 8.112, de 11 de dezembro de 1990; revoga a Lei no 11.111, de 5 de maio de 2005, e dispositivos da Lei no 8.159, de 8 de janeiro de 1991; e dá outras providências. Brasília, DF. Recuperado de http://www.planalto.gov.br/ccivil_03/_ato201 $1-2014 / 2011 /$ lei/l12527.htm

Li, D. H. (1963). The Semantic Aspect of Communication Theory and Accountancy. Journal of Accounting Research, 1(1), 102. doi: $10.2307 / 2489847$

Lu, Y. (2007). Implication of GASB statement no. 34 for reporting and accountability: the Georgia experience.Journal of Public Budgeting, Accounting \& Financial Management, 19(3), 317-337. doi: https://doi.org/10.1108/JPBA FM-19-03-2007-B003

Manes-Rossi, F. (2019). New development: Alternative reporting formats: a panacea for accountability dilemmas? Public Money \& Management, 1-4. doi: https://doi.org/10.1080/09540962.2019.1578540

Marsh, T. L., Montondon, L. G., Daniels, J. (2004). Readability of Award Winning Popular Annual Financial Reports. Journal of Accounting \& Finance Research, 12(2), 32-39.

Marsh, T. L. Montondon, L. G. (2005). A comparison of the readability of governmental annual financial reports popular reports and management discussion and analysis. Journal of Accounting and Finance Research, 13(3), p. 153-161.

Merkl-Davies, D. M., Brennan, N. M. (2017). A theoretical framework of external accounting communication. Accounting, Auditing \& Accountability Journal, 30(2), 433-469. doi: https://doi.org/10.1108/AAAJ-04-2015 $-2039$

Oliveira, A. F. L. (2016). Popular Reporting nos Municípios Portugueses. Dissertação de mestrado em Contabilidade e Finanças, Universidade de Coimbra, Coimbra, Portugal.

Platt, O. A., Neto, Cruz, F., Ensslin, S. R., Ensslin, L. (2007). Publicidade e transparência das contas públicas: obrigatoriedade e abrangência desses princípios na administração pública brasileira. Contabilidade Vista \& Revista, 18(1), 75-94.

Pérez, C. C., Hernández, A. M. L., Bolívar, M. P. R. (2005). Citizens' access to on-line governmental financial information: Practices in the European Union countries. Government Information Quarterly, 22(2), 258-276. doi: https://doi.org/10.1016/j.giq.2005.02.002 
Pinho, J. A. G. D., Sacramento, A. R. S. (2009). Accountability: já podemos traduzi-la para o português? Revista de Administração Pública, 43(6), 1343-1368.

Shannon, C. E. (1948). A mathematical theory of communication. Bell system technical journal, 27(3), 379-423.

Sharp, F. C., Carpenter, F. H., Sharp, R. F. (1998). Popular financial reports for citizens, 68(3), 34.

Smith, J. E., Smith, N. P. (1971). Readability: A Measure of the Performance of the Communication Function of Financial Reporting. The Accounting Review. American Accounting Association.

Stanley, T., Jennings, N., Mack, J. (2008). An Examination of the Content of Community Financial Reports in Queensland Local Government Authorities. Ssrn, 24(November), 411-438.

Williams, B. R. (2015). Reporting on sustainability by Australian councils-a communication perspective. Asian Review of Accounting, 23(2), 186-203. doi:10.1108/ARA-12-2013-0079

Yusuf, J. E., Jordan, M. M. (2012). Effective popular financial reports: The citizen perspective. Journal of Government Financial Management, 61(4), 44. Recuperado de https://digitalcommons.odu.edu/cgi/viewcontent.cgi?article $=1018 \&$ context $=$ publicservice_pubs

Yusuf, J. E., Jordan, M. M. (2015). Popular financial reports: tools for transparency, accountability and citizen engagement. School of Public Service Faculty Publications, 14.

Yusuf, J. E., Jordan, M. M., Neill, K. A., Hackbart, M. (2013). For the people: Popular financial reporting practices of local governments. Public Budgeting and Finance, 33(1), 95-113. doi: https://doi.org/10.1111/j.1540-5850 .2013.12003.x

Yusuf, J. W., Jordan, M. M., Franklin, A. L., Ebdon, C. (2017). How much are citizen perceptions of fiscal accountability influenced by government transparency, information access, and participation opportunities? Public Finance and Management, 17(4), 369-394. 